\title{
Variation in inbreeding depression among families and populations of Clarkia tembloriensis (Onagraceae)
}

\author{
TIMOTHY P. HOLTSFORD \\ Division of Biological Sciences, University of Missouri, Columbia, MO 65203, U.S.A.
}

\begin{abstract}
The relationship between the self-fertilization rate of a population and the severity of inbreeding depression is difficult to predict because the underlying genetics may be complex. However, it is important to understand this relationship, and the degree to which inbreeding depression varies among families within populations, if we are to understand the evolution of plant mating systems. Inbreeding depression was studied in glasshouse trials using seed derived from two populations of Clarkia tembloriensis, Cantua Creek and Idria. These had very different rates of self-fertilization $(s)$ and inbreeding coefficients $(F)(s=0.74, F=0.77$ in the CC-1 population; $s=0.16, F=0.10$ in the I-1 population). Outcrossing between these populations was equivalent to outcrossing within them; there was no evidence for outbreeding depression or increased heterosis from interpopulation crosses. The more self-fertilizing CC-1 population had fewer recessive lethal genes than the outbreeding I-1 population. However, cumulative inbreeding depression at the end of flowering was not significantly different between these populations. Inbreeding has seemingly purged the lethal genes from the $\mathrm{CC}-1$ population but overall mutational load, especially in characters that are manifest late in the life history, is still substantial despite a history of inbreeding. Variation in inbreeding depression among families within these two populations was surprisingly large. The range of variation among families was five to seven times larger than the difference in inbreeding depression between populations. Variation in inbreeding depression among families should make these populations more susceptible to the invasion of genes which increase the rate of self-fertilization.
\end{abstract}

Keywords: Clarkia, inbreeding depression, mating system, self-fertilization.

\section{Introduction}

Individuals whose parents are related by descent are often less vigorous than individuals whose parents are unrelated. The decrease in fitness of inbred progeny relative to outbred progeny is termed inbreeding depression. Inbreeding depression is an important phenomenon because it can affect the evolution of plant mating systems, the speed and efficacy of plant breeding programmes and the choice of strategy employed to sample or preserve diversity of rare or endangered populations.

The genetic basis of inbreeding depression will determine how inbreeding depression can coevolve with the mating system. Increased homozygosity can lead to inbreeding depression by two different genetic mechanisms. Homozygosity can cause deleterious recessive or partially recessive alleles to show their effects on the phenotype. Alternatively, increased homozygosity can be detrimental if the alleles at individual loci affecting fitness have a synergistic overdominant interaction so that heterozygotes are always more fit than homozygotes. If inbreeding depression is caused by the expression of deleterious recessive alleles then natural selection can decrease the severity of inbreeding depression over successive generations of inbreeding. However, the rate at which deleterious recessives are eliminated from populations and the equilibrium frequencies of these alleles depend on several genetic parameters. The number of gene loci, the degree and kinds of interactions between loci, the rate of mutation, the strength of selection, and the dominance coefficients of genes affecting fitness may all be important in determining the severity of inbreeding depression (Charlesworth \& Charlesworth, 1990; Charlesworth et al., 1990, 1991). If inbreeding depression results from the loss of overdominant 
allelic interactions as homozygosity increases then the evolution of inbreeding depression will follow a different course (Charlesworth \& Charlesworth, 1990). If the overdominance is asymmetrical (i.e. one allele confers a higher average fitness than its alternative) then inbreeding depression should decline to zero as the mating system approaches complete self-fertilization because if homozygosity is inescapable then the allele that performs better when homozygous will become fixed. Symmetrical overdominance, though unlikely, would lead to an increase in inbreeding depression as self-fertilization increases, heterozygotes become rare and both homozygotes are equally unfit (Charlesworth \& Charlesworth, 1990).

The degree to which a history of inbreeding modifies the severity of inbreeding depression is an issue on which empirical data are few and confusing (Toppings, 1989; Holtsford \& Ellstrand, 1990; Rathcke \& Real, 1993; Eckert \& Barrett, 1994; Latta \& Ritland, 1994; McCall et al., 1994). No clear picture has emerged on the degree to which mutational load may be purged by the increased efficiency of selection acting on more homozygous inbred populations. Although selection should be more efficient at decreasing the frequency of deleterious recessives when those genes are homozygous, highly inbred populations may still show substantial inbreeding depression (Karron, 1989; Holtsford \& Ellstrand, 1990; Johnston, 1992). Purging of deleterious recessive genes should be more difficult when population sizes are small enough so that drift may increase the frequency of these genes, when the deleterious alleles are more recessive, and have smaller individual effects on fitness (Charlesworth \& Charlesworth, 1987; Charlesworth et al., 1990). Furthermore, even recessive lethals may not be purged unless inbreeding exceeds a threshold value, which may be surprisingly high, even for moderate mutation rates (Lande et al., 1994). High mutation rates to deleterious recessive alleles would also impede the purging of mutational load (Johnston \& Schoen, 1995 and references therein).

Another unresolved issue is how much inbreeding depression varies among families within populations. Inter-family variation in mutational load should be critically important to mating system evolution (Uyenoyama \& Waller, 1991a,b,c). In partially inbreeding populations identity disequilibria will develop among loci influencing the mating system and loci influencing fitness (Weir \& Cockerham, 1973; Holsinger, 1988; Uyenoyama \& Waller, 1991a,b,c). If inbreeding depression is caused by deleterious recessive genes then variation among families for fitness-determining genes may allow genes for self-fertilization to invade an outbreeding population despite high average population inbreeding depression, because selfing genes will become associated with high viability genes (Uyenoyama \& Waller, 1991a). If there is overdominance for fitness then variation in inbreeding depression among families will allow outcrossing genes to become associated with high viability genes (Uyenoyama \& Waller, 1991b). The associations between genes influencing the mating system and genes influencing fitness may have as much or more effect on the course of mating system evolution as the magnitude of inbreeding depression (Holsinger, 1988; Ueynoyama \& Waller, 1991a,b,c).

This paper was motivated by these shortcomings in our empirical knowledge: does a history of inbreeding result in the purging of mutational load, and is there significant variation among families in the severity of inbreeding depression? I also ask whether outcrossing between populations results in more heterosis (the complement of inbreeding depression), than outcrossing within populations, or whether crossing between populations results in outbreeding depression (Price \& Waser, 1979; Waser \& Price, 1991; Waser, 1992). The Cantua Creek-1 (CC-1) and Idria-1 (I-1) populations of Clarkia tembloriensis were chosen for this study because their mating systems and inbreeding coefficients are quite different (selfing rates, $s=0.74$ and 0.16 ; inbreeding coefficients, $F=0.77$ and 0.10 , respectively; Holtsford \& Ellstrand, 1989), and because the genetic basis of the floral traits underlying the mating system differences in these populations have been studied (Holtsford \& Ellstrand, 1992).

\section{Materials and methods}

The study populations occur $36 \mathrm{~km}$ apart in the inner coast ranges of central California, U.S.A. (Idria-1: $36^{\circ} 33^{\prime} 00^{\prime \prime} \mathrm{N}, 120^{\circ} 50^{\prime} 00^{\prime \prime} \mathrm{W}, 457 \mathrm{~m}$ altitude, Cantua Cr-1: $36^{\circ} 24^{\prime} 30^{\prime \prime} \mathrm{N}, \quad 120^{\circ} 28^{\prime} 30^{\prime \prime} \mathrm{W}, 366 \mathrm{~m}$ ). Voucher specimens are deposited at the herbaria of the Universities of California, Riverside and Missouri. The mating system and structure of these populations is described elsewhere (Holtsford \& Ellstrand, 1989). Ten seeds from each of 15 maternal parents from the $\mathrm{CC}-1$ and $\mathrm{I}-1$ populations were sown on vermiculite and placed in a growth chamber (12 h light: $12 \mathrm{~h}$ dark, $24^{\circ} \mathrm{C}$ day, $7^{\circ} \mathrm{C}$ night). When the first set of true leaves appeared, one seedling from each field-collected maternal plant was transplanted into a $5 \mathrm{~cm}$ square pot and the seedlings 
were moved to a glasshouse. The seedlings were transplanted to $10 \mathrm{~cm}$ diameter pots when they were $15 \mathrm{~cm}$ tall and into $4 \mathrm{~L}$ pots when they were $30-40 \mathrm{~cm}$ tall.

All plants received three pollination treatments each on at least two flowers: (1) self-pollination, (2) outcrossed pollination with pollen from plants from the same population as the maternal plant, and (3) outcrossed pollination with pollen from the other population (CC-1 $\times \mathrm{I}-1$ and reciprocal). Flowers to be crossed were emasculated before anther dehiscence. Self-pollinations were achieved by wiping dehiscent anthers directly upon receptive stigmas of the same plants. Each day anthers from one newly opened flower from each plant were placed in a separate small vial for each population and allowed to dehisce. The pollen was mixed with a toothpick, and outcrossed pollinations were made with these mixtures of pollen from 15 plants. Because these pollen mixtures contained pollen from every plant in the population there may have been a small amount of self-fertilization in the outcrossed treatments. This would bias the inbreeding depression in a conservative fashion; the inclusion of selfed progeny in the outcrossed group would diminish differences among the treatments. I believe this bias to be very small because only $1 / 15$ th of the pollen in any outcrossed pollination was selfed pollen. Furthermore, in $C$. unguiculata, a very closely related species which is the presumed progenitor of $C$. tembloriensis (Vasek, 1964), selfed pollen sired only an average of 15 per cent of the offspring when applied in a 50:50 mixture with outcrossed pollen (Bowman, 1987). If the same discrimination against selfed pollen were applicable in my pollinations then 2 per cent of the outcrossed progeny would in fact be the products of self-fertilization $(1 / 15 \times 0.15 / 0.5=$ 0.02 ).

Seeds from 12 (of the 15 original) maternal plants were germinated in the growth chamber as detailed above and grown in the glasshouse. The randomized block experimental design had the following independent variables: source population $(n=2, \mathrm{CC}-1$ and I-1), maternal parent $(n=12$, nested within source population), pollination treatment $(n=3$, self-pollination, outcrossed within population, and crossed between populations), and block ( $n=6$ glasshouse benches). Three replicates were grown per bench so that each maternal parent was represented by 54 progeny, 18 in each pollination treatment. The dependent variables estimated were germination, survival to flowering, the number of flowers produced and dry weight. Dry weight estimates include above-ground tissues and the major root axis. The number of flowers, rather than the number of fruits or seeds, was used as an estimate of reproductive effort because the $\mathrm{CC}-1$ population is highly autogamous whereas I- 1 sets very few seeds in the absence of pollinators. Two lifetime fitness estimates were constructed by multiplying the proportion of surviving individuals in each treatment/ population by the flower production and by the dry weight of that group. ANOVA, Wilkes's test for normality, and Tukey's Studentized range tests were performed using SAS (SAS Institute, 1985). Correlation analyses and contingency table tests were performed using SYSTAT (version 5.2 for Macintosh, Wilkinson, 1989).

Inbreeding depression was estimated as $\delta=1-\omega_{\mathrm{sf}} / \omega_{\mathrm{ox}}$, where $\omega_{\mathrm{sf}}$ and $\omega_{\mathrm{ox}}$ are the fitness estimates of progeny resulting from selfed $\left(\omega_{\mathrm{sf}}\right)$ and outcrossed pollinations $\left(\omega_{\mathrm{ox}}\right)$. Because there were no significant differences in performance between individuals grown from outcrossing within populations vs. outcrossing between populations (see below), I used the outcrossed within-population performance to estimate lifetime $\omega_{\mathrm{ox}}$. Population inbreeding depression was estimated by pooling the performance of selfed and outcrossed plants from all families in that population. To test for variation in inbreeding depression between populations and between families the dependent variables were log-transformed and analysed by ANOVA. Because ANOVA detects additive effects a significant cross type by population interaction on untransformed data would indicate that the difference among cross types (self vs. outcross) varies between populations. A significant cross type by family or population interaction using log-transformed data indicates significant variation in the ratio of selfed to outcrossed performance and therefore indicates whether inbreeding depression varies between families or populations (Johnston \& Schoen, 1994).

Inbreeding depression was also estimated separately for each maternal parent. In cases where the average of a maternal parent's selfed offspring was greater than the average of her outcrossed offspring I estimated outbreeding depression as $\delta=-\left(1-\omega_{\mathrm{ox}}\right)$ $\left.\omega_{\mathrm{sf}}\right)$, so that $\delta$ is symmetrically distributed and bounded on [-1,1] (Agren \& Schemske, 1993). Confidence intervals for inbreeding depression estimates of maternal plants were estimated as the 2.5 th and 97.5th percentiles of the distributions of 1000 bootstrap replicates. Individuals were resampled randomly with replacement within each treatment and within each maternal parent, until the same number of individuals was chosen as was in the original maternal parent/pollination treatment group. 


\section{Results}

Germination rates were 95 per cent for the CC-1 population and 82 per cent for the I-1 population. Seeds resulting from self-pollination were less likely to germinate than outcrossed seeds in the I-1 population $\left(\chi_{2}^{2}=12.32, P=0.002\right)$ but not in the CC-1

Table 1 Germination and survivorship frequencies for three pollination treatments (self-pollinated [Selfed], crossed with pollen from the other population [Cross btw], and outcrossed with pollen from within the maternal parents' population [Cross w/in]) in two populations (Cantua Creek-1 and Idria-1) of Clarkia tembloriensis

Cantua Creek-1

Idria-1

Dead Germinated Total Dead Germinated Total

\begin{tabular}{lrrrrrr}
\hline Selfed & 9 & 206 & 215 & 55 & 160 & 215 \\
Cross btw & 11 & 202 & 213 & 27 & 183 & 210 \\
Cross w/in & 12 & 199 & 211 & 34 & 179 & 213 \\
Total & 32 & 607 & 639 & 116 & 522 & 638
\end{tabular}

Dead Flowered Total Dead Flowered Total

\begin{tabular}{lrrrrrr} 
Selfed & 31 & 184 & 215 & 76 & 139 & 215 \\
Cross btw & 24 & 189 & 213 & 43 & 167 & 210 \\
Cross w/in & 24 & 187 & 211 & 48 & 165 & 213 \\
Total & 79 & 560 & 639 & 167 & 471 & 638 \\
\hline
\end{tabular}

population $\left(\chi_{2}^{2}=0.53, P=0.77\right.$, Table 1$)$. Cumulative survivorship (including germination to flowering) was 88 per cent for the CC- 1 population and 74 per cent for the I-1 population. The plants resulting from self-pollination were less likely to survive in the more outbreeding I-1 population $\left(\chi_{2}^{2}=14.35\right.$, $P<0.001)$, while pollination treatment did not influence survivorship in the more self-fertilizing CC-1 population $\left(\chi_{2}^{2}=1.26, P=0.53\right.$, Table 1$)$.

Pollination treatment had a significant effect on survivorship $\times$ dry weight and survivorship $\times$ number of flowers $\left(F_{2,826}=63.61, F_{2,1146}=13.87\right.$, respectively, Fig. 1). Plants resulting from crossing within or between populations were not significantly different from each other but seeds derived from self-pollination produced fewer flowers and lower dry weight than either outcrossed treatment (Tukey's test, Fig. 1). The two fitness estimates (survivorship $\times$ dry weight and survivorship $\times$ number of flowers), were significantly correlated with each other in both populations ( $r=0.87, P<0.001 ; r=0.83, P=<0.005$ in $\mathrm{CC}-1$ and $\mathrm{I}-1$, respectively).

Variation in inbreeding depression was examined by dropping the outcrossed between-population treatment and performing ANOVA on log-transformed fitness estimates (Table 2). The population by cross treatment interaction was not significant for either fitness estimator indicating that inbreeding depression did not vary significantly between these two populations. However, inbreeding depression

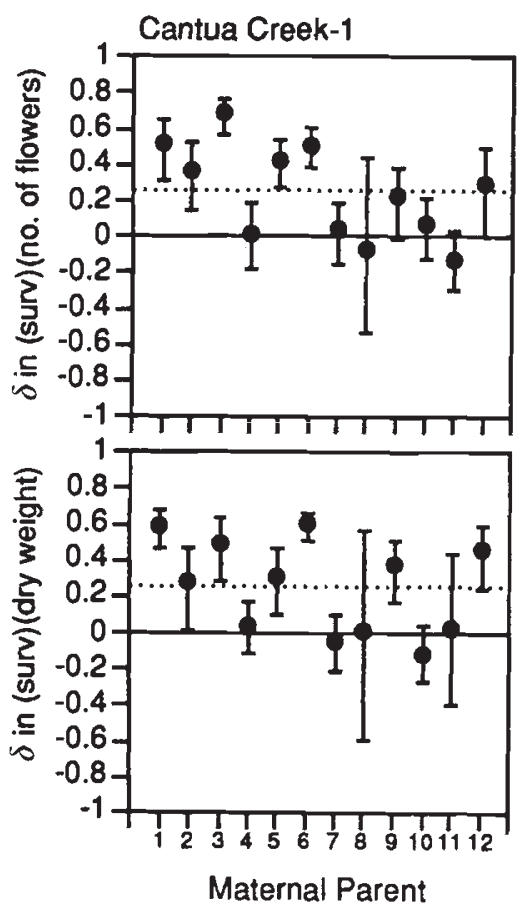

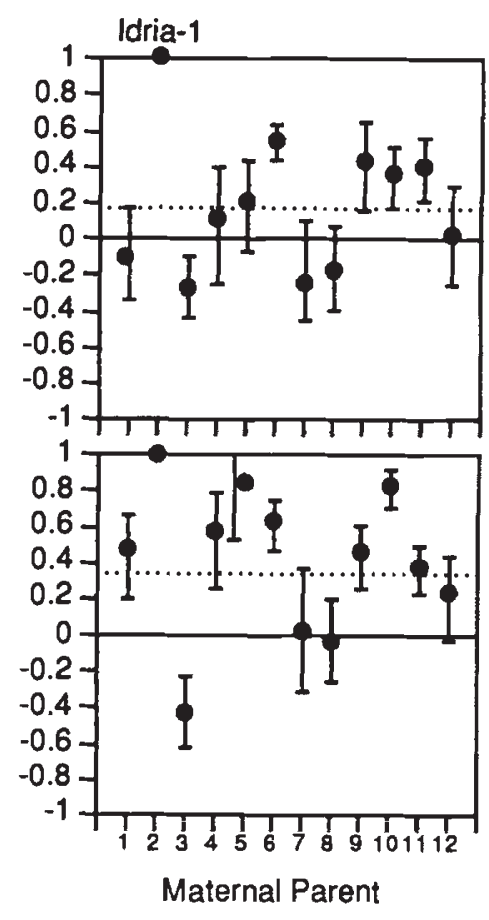

Fig. 1 Effect of pollination treatment on survivorship (surv) $\times$ final dry weight and survivorship $\times$ number of flowers in the CC-1 and I-1 populations of Clarkia tembloriensis, which differ in their natural rates of selffertilization, $s$. The treatments are: outcrossed between populations (cross btw), outcrossed within populations (cross w/in), and self-pollinated (self). Data are means $\pm 2 \mathrm{SE}$. 
Fig. 2 Variation in inbreeding depression $(\delta)$ among maternal families in two populations of Clarkia tembloriensis. Error bars denote the 2.5th and 97.5th percentiles of 1000-bootstrap distributions. The dotted lines denote the population-wide inbreeding depression.

Table 2 Analysis of variance of $\log$ (fitness estimates) for Clarkia tembloriensis. (POPN) indicates nested effects within population. 'Mom' is short for maternal parent. Bench interactions and three-way interactions were not significant and so were dropped from the model

\begin{tabular}{lcccc}
\hline Source & d.f. & Type III SS & MS & \multirow{2}{*}{$F$} \\
\hline Dependent variable: $\log [$ (no. of flowers) & (survivorship)] & & \\
Population & 1 & 0.04 & 0.04 & 0.03 \\
Maternal parent (POPN) & 22 & 32.39 & 1.47 & $4.52^{* * *}$ \\
Cross type & 1 & 7.86 & 7.86 & $24.17^{* * *}$ \\
Bench & 5 & 0.49 & 0.10 & 0.30 \\
Population $\times$ Cross type & 1 & 0.65 & 0.65 & 1.99 \\
Mom(POPN) $\times$ Cross type & 21 & 25.16 & 1.20 & $3.68^{* * *}$ \\
Dependent variable: log[(dry wt)(survivorship)] & 5.33 & & \\
Population & 1 & 28.23 & 1.28 & $4.45^{* * *}$ \\
Maternal parent (POPN) & 22 & 16.12 & 16.12 & $55.96^{* * *}$ \\
Cross type & 1 & 1.49 & 0.30 & 1.03 \\
Bench & 5 & 0.17 & 0.17 & 0.58 \\
Population $\times$ Cross type & 1 & 29.97 & 1.36 & $4.73^{* * *}$ \\
Mom(POPN) $\times$ Cross type & 22 &
\end{tabular}

***Denotes $P<0.0001$; other effects are not significant.
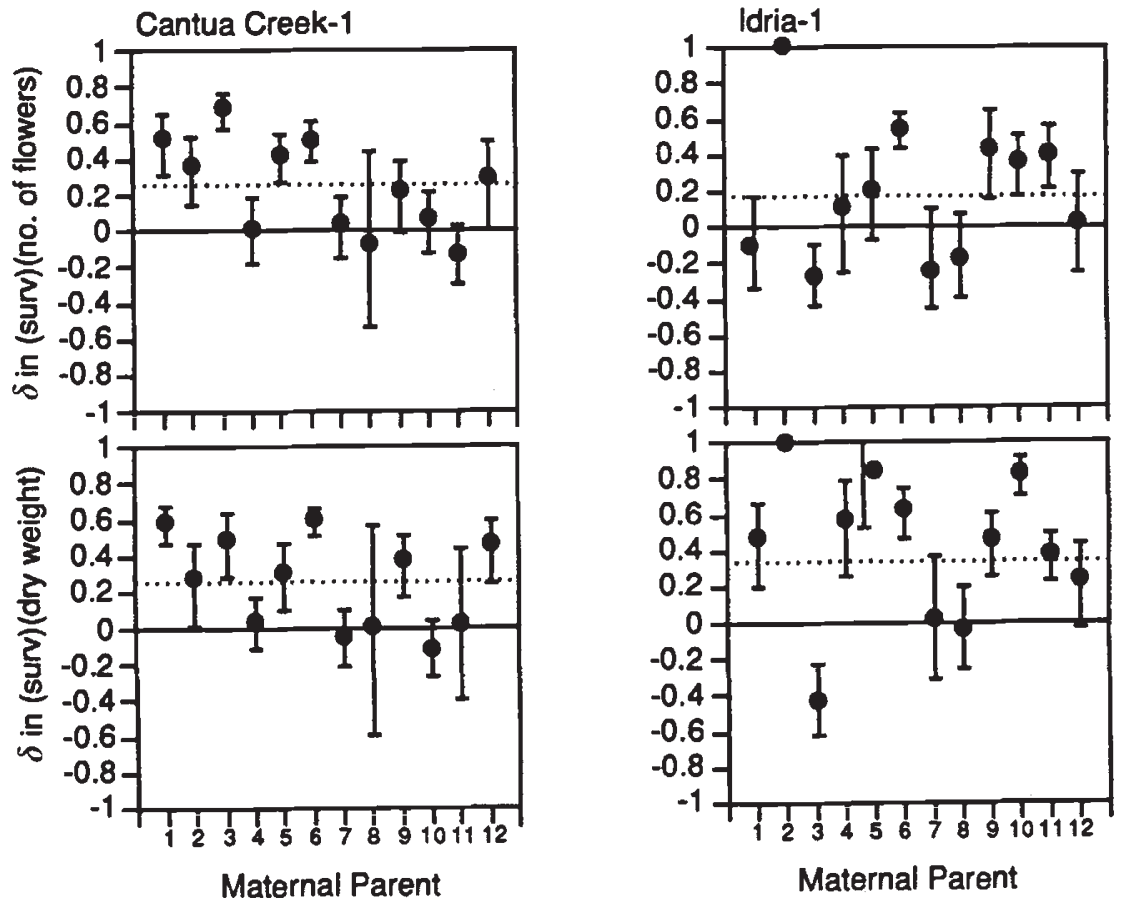

varied significantly among maternal parents, as shown by the significant interaction terms for both fitness estimates (Table 2), and by the wide range of inbreeding depression estimates for different maternal parents (Fig. 2).

The magnitude of inbreeding depression generally increased from germination through survival to flow- ering, to final lifetime dry weight and flower production, with one exception (Fig. 3). In the I-1 population, inbreeding depression in survivorship alone could account for the inbreeding depression in lifetime flower production (survivorship $\times$ number of flowers). 


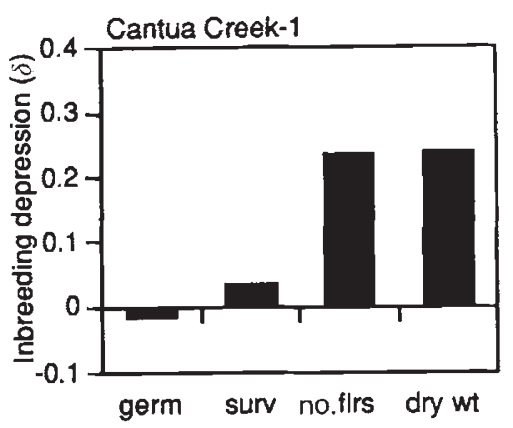

\section{Discussion}

Crossing between these two populations, which are separated by $36 \mathrm{~km}$, resulted in progeny that were equivalent in all performance measures with progeny from within-population crosses. Progeny from between-population crosses might have exhibited heterosis because they were more heterozygous than progeny from within-population crosses (expected heterozygosity at isozyme loci is 0.23 for interpopulation crosses, vs. 0.14 and 0.07 for random outcrosses within I-1 and CC-1, respectively; Holtsford \& Ellstrand, 1989). However, if the populations had diverged sufficiently from each other, either through local adaptation or by drift, then progeny from between-population crosses might have exhibited outbreeding depression (Waser \& Price, 1991; Van Treuren et al., 1991; Waser, 1992). Because I found no differences between within- and between-population crossing treatments it seems likely that a 9 or 16 per cent increase in heterozygosity was not enough to cause detectable heterosis, nor was the divergence between these populations great enough that hybrids showed outbreeding depression.

Higher homozygosity in naturally inbreeding populations should result in lower equilibrium frequencies of deleterious recessive alleles compared to more outcrossing populations (Crow, 1948; Wright, 1969; Lande \& Schemske, 1985; Charlesworth et al., 1990). Average observed heterozygosity $\left(H_{\mathrm{obs}}\right)$ is higher in the outbreeding I-1 population than in the more selfing CC-1 population so the frequency of deleterious recessive genes should also be greater in I-1 ( $H_{\text {obs }}=0.10$ in I-1 vs. 0.01 in CC-1; Holtsford \& Ellstrand, 1989). Early acting lethal mutations were more common in I-1. The naturally inbreeding $\mathrm{CC}-1$ population did not show significant prereproductive inbreeding depression in this experiment or in previous investigations (Table 1, Fig. 3 of this paper; Table 7 of Holtsford \& Ellstrand, 1990). However, plants resulting from self-pollination in the more heterozygous I-1 population survived to flower significantly less often than their outcrossed siblings.

Inbreeding depression generally increased through the life history in both populations (Fig. 3). Although the more self-fertilizing $\mathrm{CC}-1$ population may have had its early acting deleterious recessive genes purged by natural selection, lifetime inbreeding depression estimates do not differ significantly between populations - despite the almost 5-fold difference in self-fertilization rate and 10-fold difference in observed heterozygosity. The disparity between inbreeding depression in germination and survival vs. inbreeding depression in lifetime productivity may be explained by differences in selection intensity. Purging of recessive genes with larger effects on fitness proceeds much more rapidly than the purging of moderately deleterious genes (e.g. Fig. 1a of Charlesworth \& Charlesworth, 1987).

Although inbreeding should promote the purging of deleterious recessive genes the relationship between the selfing rate and inbreeding depression is not simple. The magnitude of inbreeding depression will depend not only on the mating system but on the strength of selection on, the dominance coefficients of, and the mutation rate to deleterious genes, as well as the degree and kind of epistasis among fitness-determining loci (Charlesworth \& Charlesworth, 1990; Charlesworth et al., 1990, 1991). Further complicating the relationship between the mating system and inbreeding depression are identity disequilibria among genes determining the mating system and genes influencing fitness (Holsinger, 1988; Uyenoyama \& Waller, 1991a,b,c).

The complicated relationship between the mating system and the severity of inbreeding depression is borne out by the variation in empirical results found in the literature. My previous work found that the rank of the self-fertilization rate was correlated with the rank of the severity of inbreeding depression in three C. tembloriensis populations (Holtsford \& Ellstrand, 1990; Fig. 7) - but only for three of four measures of $\delta$ and only in one of two experiments. 
Barrett \& Charlesworth (1991) demonstrated that mutational load decreased during five generations of inbreeding in a naturally outbred population, but not in a naturally selfing population of Eichornia paniculata. Latta \& Ritland (1994) used inbreeding coefficients $(F)$ estimated from isozyme data to ask whether prior inbreeding was a good predictor of inbreeding depression. Although there were negative associations between $F$ and several measures of $\delta$, only one $\delta$ estimate was significantly correlated with $F$ and populations with different inbreeding histories sometimes showed very similar levels of inbreeding depression. Other studies report weak or no association between mating system and level of inbreeding depression (Toppings, 1989; Rathcke \& Real, 1993; Eckert \& Barrett, 1994). The relationship between inbreeding history and the level of inbreeding depression may differ even between different performance traits measured on the same plants. McCall et al. (1994) found that serial inbreeding of Impatiens capensis seemed to diminish the mutational load in seed weight and biomass but that survivorship became progressively worse as inbreeding continued.

Inbreeding depression varies more among families within populations than between populations. Inbreeding depression in the outbreeding I-1 population ranged from -0.4 to 1.0 among families (Fig. 3) while differences in $\delta$ among populations were of the order of 0.1 (dotted lines in Fig. 3). Variation between families in fitness between selfed and outcrossed offspring has been demonstrated in a few studies by a significant ANOVA interaction between maternal parent and pollination treatment (Schemske, 1983; Sakai et al., 1989; Agren \& Schemske, 1993; McCall et al., 1994), but some investigations did not find any evidence for fitness variation among families (Schemske, 1983; Johnston, 1992). It is not clear how many of these maternal parent $\times$ cross type interactions would be significant if the ANOVAS had been done on log-transformed fitness estimates, as advocated by Johnston \& Schoen (1994).

By estimating $\delta$ and its underlying distribution for each maternal family one can more easily see the extent of the variation in inbreeding depression. Five to eight maternal families exhibited inbreeding depression that was significantly different from the population inbreeding depression estimate, depending on which fitness estimate and which population one considers. Family 3 from the I-1 population had a significantly negative $\delta$ by both performance estimates. Variation in $\delta$ among families is interesting because such variation may allow genes promoting inbreeding to spread even if the average inbreeding depression for the population exceeds 0.5 (or whatever the critical level might be if pollen discounting is considered; Holsinger, 1988; Uyenoyama \& Waller, 1991a). Identity disequilibria among loci develop under inbreeding (Weir \& Cockerham, 1973), so that associations among alleles at mating system loci and viability loci will not be random. Lineages which are homozygous both for genes promoting inbreeding and for partially dominant 'good' viability genes should prosper because of the higher fidelity of transmission to the next generation of the beneficial viability genes in inbreeders relative to outbreeders (Uyenoyama \& Waller, 1991a).

The primarily outbreeding I-1 population may be vulnerable to the invasion of genes which would increase self-fertilization, e.g. via gene flow from CC-1 or a similar conspecific selfing population. Although I-1 has a higher frequency of lethal genes than the more selfing CC- 1 population, lifetime $\delta$ estimates are below 0.5 , the critical level of inbreeding depression that prevents the spread of selfing genes in simple models of mating system evolution (e.g. Maynard Smith, 1978 \& model 1a of Lloyd, 1979). However, I might have underestimated inbreeding depression because I estimated $\delta$ in the glasshouse and because I could not quantify inbreeding effects in all fitness-related traits, e.g. male reproductive function.

Pollen discounting may retard the evolution of selfing in Clarkia. Selfing populations of C. tembloriensis produce less total pollen and have lower pollen:ovule ratios than outcrossing populations. Hence, selfers' potential for male reproductive success is lower than that of outcrossers (Vasek \& Weng, 1988). The estimated pollen:ovule ratio of I-1 is $148: 1$ while that of CC-1 is $73: 1$ (collections T2 and T6 of Vasek \& Weng, 1988). The critical level of $\delta$ that would prevent the spread of a selfing gene would be less than 0.5 if invading selfers suffered not only inbreeding depression but also reduced ability to transmit the selfing genes via male function (Holsinger et al., 1984). Further complicating the prediction of the fate of selfing genes is that the floral traits which promote selfing (reduced antherstigma separation and shortened protandry) are not simply inherited. Segregation of $F_{2}$ and backcross progeny from hybrids between I- 1 and $\mathrm{CC}-1$ showed that genetic divergence in mating system traits between these populations is polygenic (Holtsford \& Ellstrand, 1992).

The marked variation among maternal families in inbreeding depression should facilitate the invasion of selfing genes. Because highly inbred populations 
still show significant inbreeding depression (see also Holtsford \& Ellstrand, 1990), it is likely that deleterious recessive genes (not overdominant interactions) are responsible for the inbreeding depression in these Clarkia populations. As identity disequilibria are established, those families with selfing genes and 'good' viability genes should prosper at the expense of lineages with other combinations of mating system and viability alleles (Uyenoyama \& Waller, 1991a). For example, if a gene promoting selfing were crossed into a genetic background similar to that of I- 1 families $3,7,8$ or 12 then these lineages should do very well because they seemingly suffer no inbreeding depression. Furthermore, the genes promoting selfing would increase the fidelity with which both the 'good' viability genes and the selfing genes were transmitted to the offspring.

\section{Acknowledgements}

I would like to thank Tammy Cornine, Chris Jungbluth, Troy Richey and Kim McCue for their help in the glasshouse. The comments of Kim McCue, Anthony Ippolito and two anonymous reviewers improved the manuscript. This work was supported by the University of Missouri Research Board award 93060 .

\section{References}

AGREN, J. AND SCHEMSKE, D. W. 1993. Outcrossing rate and inbreeding depression in two annual monoecious herbs, Begonia hirsuta and B. semiovata. Evolution, 47, $125-135$.

BARRETT, S. C. H. AND CHARLESWORTH, D. 1991. Effects of a change in the level of inbreeding on the genetic load. Nature, 352, 522-524.

BOWMAN, R. N. 1987. Cryptic self-incompatibility and the breeding system of Clarkia unguiculata (Onagraceae). Am. J. Bot., 74, 471-476.

CHARLESWORTH, B., MORGAN, M. T. AND CHARLESWORTH, D. 1991. Multilocus models of inbreeding depression with synergistic selection and partial self-fertilization. Genet. Res., 57, 177-194.

CHARLESWORTH, D. AND CHARLESWORTH, B. 1987. Inbreeding depression and its evolutionary consequences. Ann. Rev. Ecol. Syst., 18, 237-268.

CHARLESWORTH, D. AND CHARLESWORTH, B. 1990. Inbreeding depression with heterozygote advantage and its effect on selection for modifiers changing the outcrossing rate. Evolution, 44, 870-888.

CHARLESWORTH, D., MORGAN, M. T. AND CHARLESWORTH, B. 1990. Inbreeding depression, genetic load, and the evolution of outcrossing rates in a multilocus system with no linkage. Evolution, 44, 1469-1489.

CROW, J. F. 1948. Alternative hypotheses of hybrid vigor.
Genetics, 33, 477-487.

ECKERT, C. G. AND BARRETT, s. C. H. 1994. Inbreeding depression in partially self-fertilizing Decodon verticillatus (Lythraceae): population-genetic and experimental analyses. Evolution, 48, 952-964.

HOLSINGER, K. E. 1988. Inbreeding depression doesn't matter: the genetic basis of mating system evolution. Evolution, 42, 1235-1244.

HOLSINGER, K. E., FELDMAN, M. W. AND CHRISTIANSEN, F. B. 1984. The evolution of self-fertilization in plants: a population genetic model. Am. Nat., 124, 446-453.

HOLTSFORD, T. P. AND ELLSTRAND, N. C. 1989. Variation in outcrossing rate and population genetic structure of Clarkia tembloriensis (Onagraceae). Theor. Appl. Genet., 78, 480-488.

HOLTSFORD, T. P. AND ELLSTRAND, N. C. 1990. Inbreeding effects in Clarkia tembloriensis (Onagraceae) populations with different natural outcrossing rates. Evolution, 44, 2031-2046.

HOLTSFORD, T. P. AND ELLSTRAND, N. C. 1992. Genetic and environmental variation in floral traits affecting outcrossing rate in Clarkia tembloriensis (Onagraceae). Evolution, 46, 216-225.

JOHNSTON, M. O. 1992. Effects of cross and self-fertilization on progeny fitness in Lobelia cardinalis and $L$. siphilitica. Evolution, 46, 688-702.

JOHNSTON, M. O. AND SCHOEN, D. J. 1994. On the measurement of inbreeding depression. Evolution, 48, 1735-1741.

JOHnston, M. O. AND SCHOEN, D. J. 1995. Mutation rates and dominance levels of genes affecting total fitness in two angiosperm species. Science, 267, 226-229.

KARRON, J. D. 1989. Breeding systems and the level of inbreeding depression in geographically restricted and widespread species of Astragalus (Fabaceae). Am. J. Bot., 76, 331-340.

LANDE, R. AND SCHEMSKE, D. w. 1985. The evolution of self-fertilization and inbreeding depression in plants. I. Genetic models. Evolution, 39, 24-40.

LANDE, R., SCHEMSKE, D. w. AND SChultz, S. T. 1994. High inbreeding depression, selective interference among loci, and the threshold selfing rate for purging recessive lethal mutations. Evolution, 48, 965-978.

LATTA, R. AND R1TLAND, к. 1994. The relationship between inbreeding depression and prior inbreeding among populations of four Mimulus taxa. Evolution, 48, 806-817.

LLOYD, D. G. 1979. Some reproductive factors affecting the selection of self-fertilization in plants. Am. Nat., 113, $67-79$.

MAYNARD Smith, J. 1978. The Evolution of Sex. Cambridge University Press, Cambridge, U.K.

MCCALL, C., WALLER, D. M. AND MITCHELL-OLDS, T. 1994. Effects of serial inbreeding on fitness components in Impatiens capensis. Evolution, 48, 818-827.

OUBORG, N. J. AND VAN TRUEREN, R. 1994. The significance of genetic erosion in the process of extinction. IV. Inbreeding load and heterosis in relation to population size in the mint Salvia pratensis. Evolution, 48 ,

(C) The Genetical Society of Great Britain, Heredity, 76, 83-91. 
996-1008.

PRICE, M. V. AND WASER, N. M. 1979. Pollen dispersal and optimal outcrossing in Delphinium nelsoni. Nature, 277, 294-297.

RATHCKE, B. AND REAL, L. 1993. Autogamy and inbreeding depression in mountain laurel, Kalmia latifolia (Ericaceae). Am. J. Bot., 80, 143-146.

SAKAI, A. K., KAROLY, K. AND WELlER, S. G. 1989. Inbreeding depression in Schiedea globosa and S. salicaria (Caryophyllaceae), subdioecious and gynodioecious Hawaiian species. Am. J. Bot., 76, 437-444.

SAS Institute, 1985. SAS User's Guide: Basics and Statistics. SAS Institute, Cary, North Carolina.

SCHEMSKE, D. W. 1983. Breeding system and habitat effects on fitness components in three neotropical Costus (Zingiberaceae). Evolution, 37, 523-539.

TOPPINGS, P. 1989. The Significance of Inbreeding Depression to the Evolution of Self-fertilization in Eichornia paniculata (Spreng.) Solms. (Pontederiaceae). M.S. Thesis, University of Toronto.

UYENOYAMA, M. K. AND WALlER, D. M. 1991a. Coevolution of self-fertilization and inbreeding depression. I. Mutation-selection balance at one and two loci. Theor. Pop. Biol., 40, 14-46.

UYENOYAMA, M. K. AND WALleR, D. M. 1991b. Coevolution of self-fertilization and inbreeding depression. II. Symmetric overdominance in viability. Theor. Pop. Biol, 40, 47-77.

UYENOYAMA, M. K. AND WALleR, D. M. 1991c. Coevolution of self-fertilization and inbreeding depression. III. Homozygous lethal mutations at multiple loci. Theor. Pop. Biol., 40, 173-210.

VAN TREUREN, R., BIJLSMA, R., VAN DELDEN, W. AND OUBORG, N. J. 1991. The significance of genetic erosion in the process of extinction. I. Genetic differentiation in Salvia pratensis and Scabiosa columbaria in relation to population size. Heredity, 66, 181-189.

VASEK, F. C. 1964. The evolution of Clarkia unguiculata derivatives adapted to relatively xeric environments. Evolution, 18, 26-42.

VASEK, F. C. AND WENG, v. 1988. Breeding systems of Clarkia sect. Phaeostoma (Onagraceae): I. Pollen-ovule ratios. Syst. Bot., 13, 336-350.

WASER, N. M. 1992. Population structure, optimal outbreeding, and assortative mating in angiosperms. In: Thornhill, N. W. (ed.) The Natural History of Inbreeding and Outbreeding: Theoretical and Empirical Perspectives. University of Chicago Press, Chicago.

WASER, N. M. AND PRICE, M. V. 1991. Outcrossing distance effects in Delphinium nelsonii: pollen loads, pollen tubes, and seed set. Ecology, 72, 171-179.

WEIR, B. S. AND COCKERHAM, C. C. 1973. Mixed self and random mating at two loci. Genet. Res., 21, 247-262.

WILkInson, L. 1989. SYSTAT: The System for Statistics. Systat Inc., Evanston, Illinois.

WRIGHT, s. 1969. Evolution and Genetics of Populations, vol. 2, The Theory of Gene Frequencies. University of Chicago Press, Chicago. 